\title{
手性多取代环戊二烯配体的合成及应用
}

\author{
梁昊 汪 君* \\ (中山大学化学学院 广州 510275)
}

\section{Synthesis and Application of Chiral Multisubstituted Cyclopentadienyl Ligands}

\author{
Liang, Hao Wang, Jun* \\ (School of Chemistry, Sun Yat-Sen University, Guangzhou 510275)
}

2012 年, Cramer 小组 ${ }^{[1]}$ 与 Rovis 和 Ward 小组 ${ }^{[2]}$ 几乎 同时报道了手性环戊二烯 $(\mathrm{Cp})$ 铑催化剂可以高效、高对 映选择性地实现不对称碳氢键活化反应. 其中, 前者使 用的是甘露醇衍生的具有手性骨架的 $\mathrm{Cp}$ 铑催化剂，而 后者则是利用生物素(biotin)与亲和素(avidin)的强结合 作用, 将非手性五甲基 $\mathrm{Cp}$ 铑络合物牢固绑定在人工酶 的手性空腔中, 进而形成手性催化剂. 自此, 手性 $\mathrm{Cp}$ 金 属络合物催化成为科学家们探索不对称碳氢活化的重 要策略之一. ${ }^{[3]}$

另一方面, Rovis 等 ${ }^{[4]}$ 多个研究小组发现, $\mathrm{Cp}$ 结构上 取代基的电子效应及位阻效应对碳氢活化反应的速率 和各种选择性有着显著影响. 因此, 开发手性多取代 $\mathrm{Cp}$ 配体对不对称碳氢活化研究具有重要科学意义. 近年 来, 科学家们在新型手性 $\mathrm{Cp}$ 金属催化剂开发上取得了 可喜的进展, 但研究焦点主要集中在手性骨架的创新 上, 而对于手性多取代 $\mathrm{Cp}$ 配体的合成研究却很少 ${ }^{[5]}$. 近 日, 中国科学院上海有机化学研究所游书力课题组 ${ }^{[6]}$ 在 该方面取得了重要进展, 实现了手性多取代 $\mathrm{Cp}$ 配体的 发散性合成, 并将相关 $\mathrm{Cp}$ 金属催化剂成功应用于手性 异吲哚酮的对映选择性合成中.

如 Scheme 1 所示, 从手性联菜二炔 $(R)-1$ 出发, 利 用 $[2+2+1]$ 成环反应 ${ }^{[7]}$ 制得了关键手性中间体环戊二 烯酮(R)-2. 随后, 使用各种格氏试剂或锂试剂对其羰基 进行亲核加成, 便引入了不同的 $\mathrm{R}^{2}$ 取代基(如甲基、异 丙基和苯基). 而三甲基硅基(TMS)则可方便地转化为不 同的 $\mathrm{R}^{3}$ 取代基(如氢或甲基). 待合成得到手性多取代 $\mathrm{Cp}$ 配体后，将其与三氯化铑反应，可制得相应的铑络合 物 $(R)-\mathrm{Cp}^{\mathrm{m}} \mathbf{R h} 1 \sim(R)-\mathrm{Cp}^{\mathrm{m}} \mathbf{R h} 6$. 值得一提的是, 与联䒺
$\mathrm{Cp}$ 配体的经典合成方法 ${ }^{[8]}$ 相比，该合成策略在 $\mathrm{Cp}$ 环的 取代基调控方面具有巨大优势, 为合成品种丰富的手性 多取代 $\mathrm{Cp}$ 配体提供了有效方法.<smiles>[R]c1cc2ccccc2c(-c2c(CC#CC)c([R])cc3ccccc23)c1CC#CC</smiles>

$(R)-1$

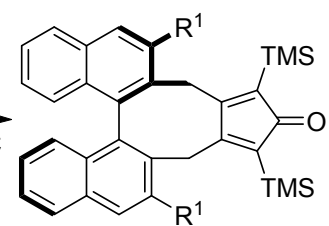

$(R)-2$

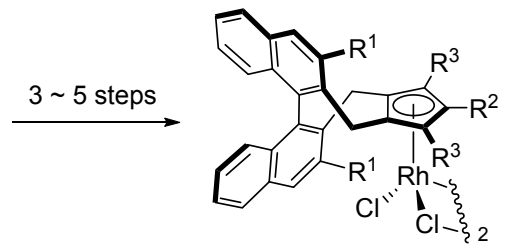

$(R)-\mathrm{Cp}^{\mathrm{m}} \mathrm{Rh} 1\left(\mathrm{R}^{1}=\mathrm{R}^{3}=\mathrm{H}, \mathrm{R}^{2}=\mathrm{Me}\right)$

(R)-Cp ${ }^{\mathrm{m}} \mathrm{Rh} 2\left(\mathrm{R}^{1}=\mathrm{R}^{3}=\mathrm{H}, \mathrm{R}^{2}=i-\mathrm{Pr}\right)$

(R)-Cp ${ }^{\mathrm{m}} \mathrm{Rh} 3\left(\mathrm{R}^{1}=\mathrm{R}^{3}=\mathrm{H}, \mathrm{R}^{2}=\mathrm{Ph}\right)$

$(R)-\mathrm{Cp}^{\mathrm{m}} \mathrm{Rh} 4\left(\mathrm{R}^{1}=\mathrm{H}, \mathrm{R}^{2}=\mathrm{R}^{3}=\mathrm{Me}\right)$

(R)-Cp ${ }^{\mathrm{m}} \mathrm{Rh} 5\left(\mathrm{R}^{1}=\mathrm{OMe}, \mathrm{R}^{2}=\mathrm{R}^{3}=\mathrm{Me}\right)$

$(R)-\mathrm{Cp}^{\mathrm{m}} \mathrm{Rh} 6\left(\mathrm{R}^{1}=\mathrm{Ph}, \mathrm{R}^{2}=\mathrm{R}^{3}=\mathrm{Me}\right)$

图式 1 多取代手性环戍二烯铑络合物的合成 Scheme 1 Synthesis of multisubstituted chiral cyclopentadienyl rhodium complexes

随后对上述手性多取代 $\mathrm{Cp}$ 催化剂的应用开展了研 究, 并实现了第一例苯甲酰胺类底物 3 和烯烃 4 的高对 映选择性碳氢活化 $[4+1]$ 环化反应, 得到了手性异吲哚 酮类化合物 6 (Scheme $2 b$ ). 值得注意的是，在 $\mathrm{CpRh}^{\mathrm{III}}$ 催 化下, 苯甲酰胺类底物与末端烯烃通常发生 $[4+2]$ 环化 反应生成二氢异喹啉酮 5 (Scheme 2a) ${ }^{[1]}$. 催化剂節选实 验表明 $(R)-C p^{\mathrm{m}} \mathbf{R h} 4$ 效果最佳. 进一步优化条件后, 他们

* Corresponding author. E-mail: wangjun23@mail.sysu.edu.cn. Published online May 3, 2020. 
发现最佳可以 $82 \%$ 的收率和 $90 \%$ 的 $e e$ 值得到标准产物. 底物普适性研究表明, 4-位和 3-位取代的苯乙烯反应效 果较好 $(68 \% \sim 92 \%$ 收率, 89\% 93\% ee), 而 2-位取代的 苯乙烯对映选择性较低( $89 \%$ ～91\%收率，0～31\% ee). 另外, 酰胺底物的兼容性也较好, 大多能获得 $80 \%$ 94\%收率和 $77 \% \sim 90 \%$ ee. 当把反应规模扩大到 1.0 $\operatorname{mmol}($ 酰胺底物) 时, 反应结果与小规模实验时相当 (Scheme 2b).

(a) [4+2]反应 (已有报道)

$$
\overbrace{3}^{\mathrm{N}_{\mathrm{H}^{-}}}
$$

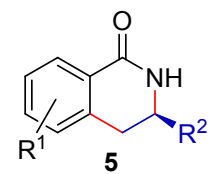

(b) 不对称 $[4+1]$ 反应 (游书力课题组)<smiles>[R][R]1cccc2c1C(Cc1ccccc1)NC2=O</smiles><smiles>O=C1NC(Cc2ccccc2)c2ccccc21</smiles>

$82 \%$ yield, $90 \%$ ee $84 \%$ yield, $92 \%$ ee (1.0 mmol scale)<smiles>O=C1NC(CCl)c2ccccc21</smiles><smiles>O=[N+]([O-])c1ccccc1</smiles>
$88 \%$ yield, $94 \%$ ee $\quad 89 \%$ yield, $89 \%$ Br<smiles>O=C1NC(Cc2ccccc2Cl)c2ccccc21</smiles><smiles>Cc1ccc2c(c1)C(Br)NC2=O</smiles>
$82 \%$ yield, $90 \%$ ee<smiles>O=C1NC(Cc2ccccc2)c2ccc(C(F)(F)F)cc21</smiles>

$57 \%$ yield, $85 \%$ ee<smiles>O=C1NC(Cc2ccccc2)c2cc3ccccc3cc21</smiles>

$88 \%$ yield, $74 \%$ ee

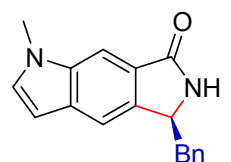

$73 \%$ yield, $81 \%$ ee
图式 2 手性异吲哚酮的不对称合成

Scheme 2 Asymmetric synthesis of isoindolinones
基于 Scheme 3 所示的同位素示踪实验，作者提出 了可能的催化循环. 首先, 铑催化酰胺底物发生 $\mathrm{C}-\mathrm{H}$ 键活化形成铑杂五元环物种. 其次, 烯烃与铑配位并发 生迁移插入反应得到铑杂七元环物种. 再次, 它经过 $\beta-\mathrm{H}$ 消除和迁移插入反应生成铑杂六元环中间体. 最后, 该中间体经过还原消除, $\mathrm{N}-\mathrm{O}$ 键对铑(I)氧化加成以及 质子化生成手性异吲哚酮产物, 同时再生铑催化剂. 需 要指出的是，该反应机理明显不同于以往报道的苯甲酰 胺类底物与缺电子烯烃 $[4+1]$ 环化反应所经历的氧化烯 基化/麦克尔加成串联反应机理.

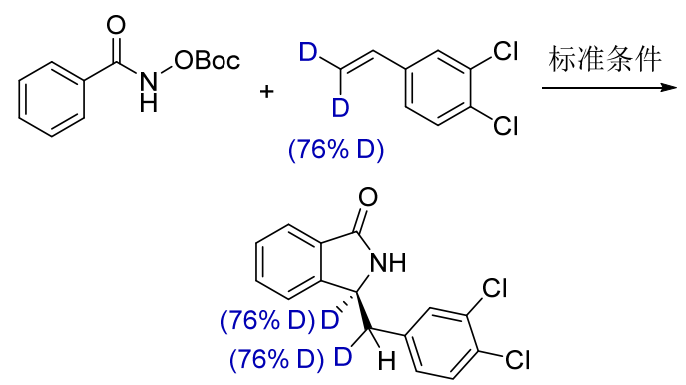

图式 3 同位素示踪实验

Scheme 3 Isotope labeling experiment

综上所述, 游书力课题组报道了一种新颖的合成手 性 $\mathrm{Cp}$ 配体的方法, 特别是为手性多取代 $\mathrm{Cp}$ 配体合成提 供了新思路和新路径. 另外，他们利用该类手性催化剂 首次实现了苯甲酰胺类底物与烯烃的高对映选择性 $[4+1]$ 环化反应, 为手性异吲哚酮的不对称合成提供了 新方法.

\section{References}

[1] Ye, B.; Cramer, N. Science 2012, 338, 504.

[2] Hyster, T. K.; Knörr, L.; Ward, T. R.; Rovis, T. Science 2012, 338, 500.

[3] Newton, C. G.; Kossler, D.; Cramer, N. J. Am. Chem. Soc. 2016, $138,3935$.

[4] Piou, T.; Rovis, T. Acc. Chem. Res. 2018, 51, 170.

[5] (a) Smits, G.; Audic, B.; Wodrich, M. D.; Corminboeuf, C.; Cramer, N. Chem. Sci. 2017, 8, 7174.

(b) Sun, Y.; Cramer, N. Chem. Sci. 2018, 9, 2981.

[6] Cui, W.-J.; Wu, Z.-J.; Gu, Q.; You, S.-L. J. Am. Chem. Soc. 2020 142,7379

[7] Shibata, T.; Yamashita, K.; Takagi, K.; Ohta, T.; Soai, K. Tetrahedron 2000, 56, 9259.

[8] Ye, B.; Cramer, N. J. Am. Chem. Soc. 2013, 135, 636.

(Cheng, F.) 